\title{
Mass and density of individual frozen hydrometeors
}

\author{
Karlie N. Rees ${ }^{1}$, Dhiraj K. Singh ${ }^{2}$, Eric R. Pardyjak ${ }^{2}$, and Timothy J. Garrett ${ }^{1}$ \\ ${ }^{1}$ Department of Atmospheric Sciences, University of Utah, Salt Lake City, UT, USA \\ ${ }^{2}$ Department of Mechanical Engineering, University of Utah, Salt Lake City, UT, USA
}

Correspondence: Timothy J. Garrett (tim.garrett@utah.edu)

Received: 27 February 2021 - Discussion started: 6 April 2021

Revised: 9 August 2021 - Accepted: 15 August 2021 - Published: 24 September 2021

\begin{abstract}
A new precipitation sensor, the Differential Emissivity Imaging Disdrometer (DEID), is used to provide the first continuous measurements of the mass, diameter, and density of individual hydrometeors. The DEID consists of an infrared camera pointed at a heated aluminum plate. It exploits the contrasting thermal emissivity of water and metal to determine individual particle mass by assuming that energy is conserved during the transfer of heat from the plate to the particle during evaporation. Particle density is determined from a combination of particle mass and morphology. A Multi-Angle Snowflake Camera (MASC) was deployed alongside the DEID to provide refined imagery of particle size and shape. Broad consistency is found between derived mass-diameter and density-diameter relationships and those obtained in prior studies. However, DEID measurements show a generally weaker dependence with size for hydrometeor density and a stronger dependence for aggregate snowflake mass.
\end{abstract}

\section{Introduction}

Predictions of precipitation amount, location, and duration have been shown to be especially sensitive to parameterized expressions for how fast a hydrometeor falls (Rutledge and Hobbs, 1984; Reisner et al., 1998; Hong et al., 2004; Fovell and Su, 2007; Lin et al., 2010; Liu et al., 2011; Iguchi et al., 2012; Thériault et al., 2012), affecting forecasts of hurricane trajectories (Fovell and Su, 2007) and storm lifetimes (Garvert et al., 2005; Colle et al., 2005; Milbrandt et al., 2010). From the perspective of fluid dynamics, fall speed can be related to the mass and density of precipitation particles (Böhm, 1989). Observationally, one of the most frequently cited datasets that lies at the heart of current bulk microphys- ical parameterizations (e.g. Reisner et al., 1998; Hong et al., 2004; Tao et al., 2003) comprises just 376 snowflakes captured and photographed in the Cascade mountain range. Individual hydrometeors were melted on a sheet of plastic film, from which relationships were obtained between hydrometeor mass, fall speed, and diameter as a function of particle habit and, in the case of graupel, density (Locatelli and Hobbs, 1974). Despite its limited scope, later numerical studies (Böhm, 1989; Khvorostyanov and Curry, 2002; Heymsfield and Westbrook, 2010; Kubicek and Wang, 2012) and ground-based disdrometer measurements (Kruger and Krajewski, 2002; Barthazy et al., 2004; Yuter et al., 2006; Newman et al., 2009) have lent general support to this reference dataset, although concerns remain about geographic and temporal specificity, measurement limitations (Yuter et al., 2006; Battaglia et al., 2010), and the ability to quantify the extent of riming (Barthazy and Schefold, 2006; Brandes et al., 2008).

Particle density measurements have proven more difficult to ascertain as they require, in addition to mass, an estimate of particle volume. This may be reasonably obtained for quasi-spherical particles such as lump graupel (Locatelli and Hobbs, 1974), but the task is considerably more challenging when snow particles are formed from ice crystal aggregation. A possible approach is to infer density from fallen snow using column measurements (Conger and McClung, 2009), capacitance probes (Dent et al., 1998), or a combination of a camera for snow depth and an electric scale for snow mass (Muramoto et al., 1995). Muramoto et al. (1995) and Brandes et al. (2007) measured the bulk mass of snowflakes using a weighing gauge, from which the bulk volume was determined with 2D camera imagery of individual snowflakes. Tiira et al. (2016) determined a volume flux weighted snow density for a population of snowflakes using particle size distribution, fall speed, and a weighing gauge to estimate 
the mass, as well as 2D camera imagery to determine effective diameter and volume. However, snow undergoes compaction and melting on the ground; thus, the relationship to individual particle density in the air is approximate (Brun et al., 1992). To obtain individual snowflake particle density, Magono and Nakamura (1965) collected individual wet and dry snowflakes on a piece of dyed filter paper, from which the outline of the flake was manually measured. Individual volume was inferred from the major and minor axes of the outline of snow and the mass from the outline of the melted snowflake. Holroyd (1971) also made measurements of the major and minor axes of powder snow and dendrites from (Magono and Nakamura, 1965). A limitation of these datasets is that they were necessarily small given the manual nature of the effort.

Here, we present continuous measurements of individual masses of frozen hydrometeors using a new instrument, the Differential Emissivity Imaging Disdrometer (DEID). DEID data (Rees et al., 2021) are combined with photographic imagery obtained using a Multi-Angle Snowflake Camera (MASC) (Garrett et al., 2012) to obtain estimates of particle density.

\section{Methods}

All measurements described in this study were acquired at a meteorological measurement tower placed at the mouth of Red Butte Canyon (40.76857, -111.82614) in Salt Lake City, Utah, at $1547 \mathrm{~m}$ elevation in January and February 2020. More details about the site and measurement campaign are provided by Singh et al. (2021).

\subsection{Particle mass from thermal imaging}

The Differential Emissivity Imaging Disdrometer (DEID) (Singh et al., 2021) consists of a thermal camera operating at a frequency between 2 and $12 \mathrm{~Hz}$ pointed at an aluminum plate placed atop a hotplate maintained at a selfsustained temperature of $85^{\circ} \mathrm{C}$. The camera distinguishes hydrometeors as they melt and evaporate as white regions on a black background (Fig. 1) due to the contrasting infrared emissivities of water $(\epsilon \approx 0.96)$ and aluminum $(\epsilon \approx 0.03)$. A small strip of polyimide tape $(\epsilon \approx 0.95)$ is applied to the aluminum plate to provide a reference temperature, as well as a pixel-to-length dimension conversion based on the tape's known width. The effective collection area of the DEID was $A \approx 7 \mathrm{~cm} \times 5 \mathrm{~cm}$, and the per pixel resolution of imaged particles $p$ was $190 \mu \mathrm{m}$. Processing of the thermal camera imagery yields the hydrometeor area on the plate, the temperature difference between the water and the plate, and the evaporation time.

Individual particle mass is determined using the DEID by employing the assumption that the heat gained by a hydrometeor is equivalent to the heat lost by the plate during the pro-

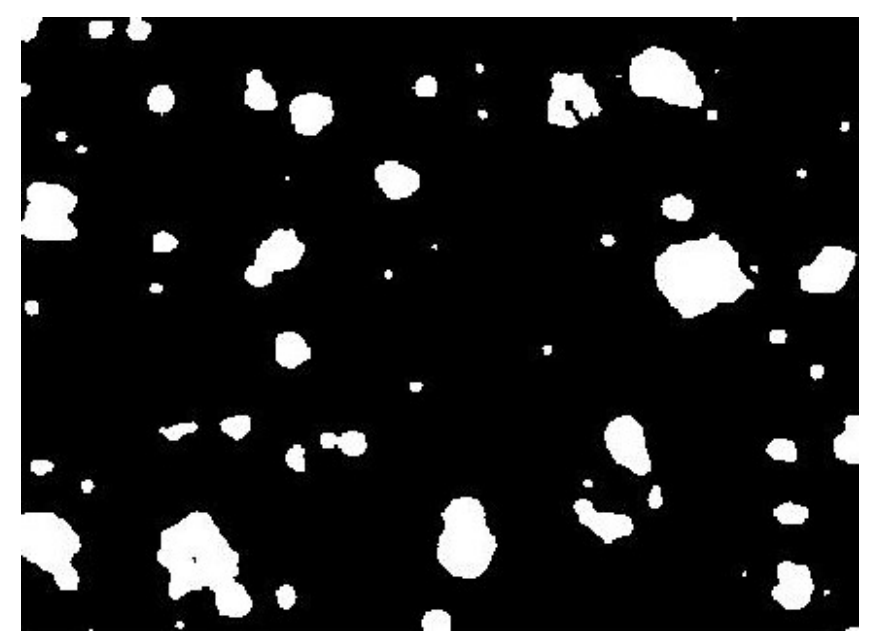

Figure 1. Thermal camera imagery from the DEID, showing regions of high-emissivity water (white) on a low-emissivity aluminum plate (black).

cess of melting and evaporation. The heat balance equation is

$c_{p} \Delta T \int \mathrm{d} M+L_{\text {eqv }} \int \mathrm{d} M=\int_{0}^{t} \frac{K}{H} A(t)\left(T_{\mathrm{p}}-T_{\mathrm{w}}(t)\right) \mathrm{d} t$,

where $c_{p}$ is the specific heat capacity of water at constant pressure, $\Delta T$ is the difference in temperature between 0 and time $(t), M$ is the mass of the hydrometeor, and $L_{\text {eqv }}$ is the equivalent latent heat required for the conversion of the hydrometeor to gas. For liquid precipitation, $L_{\text {eqv }}=L_{\mathrm{v}}$, where $L_{\mathrm{v}}$ is the latent heat of vaporization of water. For solid precipitation, $L_{\text {eqv }}=L_{\mathrm{v}}+L_{\mathrm{f}}$, where $L_{\mathrm{f}}$ is the latent heat fusion for water. $K$ is the thermal conductivity of the aluminum plate, $H$ is the plate thickness, $A(t)$ is the cross-sectional area of the water droplet at time $t, T_{\mathrm{p}}$ is the temperature of the hotplate, and $T_{\mathrm{w}}(t)$ is the temperature of the water at time $t$. Taking

$\int \mathrm{d} M=K_{\mathrm{d}} \int_{0}^{t} A(t)\left(T_{\mathrm{p}}-T_{\mathrm{w}}(t)\right) \mathrm{d} t$,

a single calibrated constant $K_{\mathrm{d}}$ for the plate was determined experimentally by applying known masses of water from a micropipette to the plate (see Appendix A for the derivation of $K_{\mathrm{d}}$ ). The heat balance equation was found in a laboratory setting to be highly insensitive to ambient winds, temperature, and humidity (Singh et al., 2021).

The temperature difference between the plate and water on the plate $\left(\Delta T=T_{\mathrm{p}}-T_{\mathrm{w}}(t)\right)$ can be determined using the mean pixel intensity of the particle in the thermal camera imagery (see Appendix B). The mass calculation then simplifies to

$M=K_{d} \Delta T \int A(t) \mathrm{d} t$. 


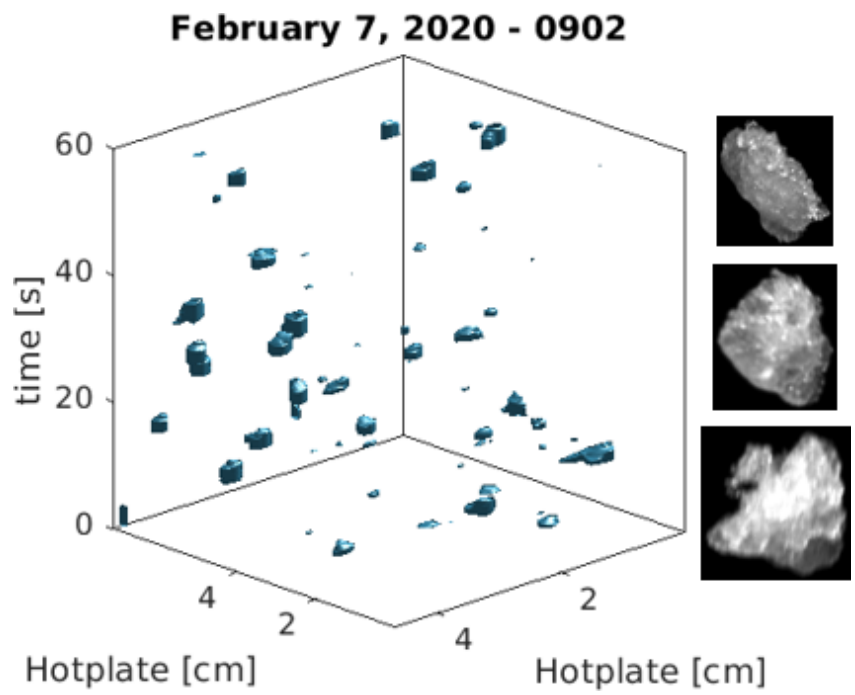

Figure 2. Evaporation volumetric profiles on the DEID plate in a space of imaged area and time $V_{t}=\int A(t) \mathrm{d} t$ for graupel.

Three-dimensional regions integrated over particle area and evaporation time were constructed for each particle during the melting process defined by $V_{t}=\int A(t) \mathrm{d} t$ so that from Eq. (2), $M=K_{d} V_{t} \Delta T$. An example of a 1 min time interval with $3 \mathrm{D}$ volumetric regions representing each individual particle is shown in Fig. 2 for graupel. Additional 3D representations for other snowflake types are shown in Appendix B.

\subsection{Hydrometeor photography}

The Multi-Angle Snowflake Camera (MASC) (Garrett et al., 2012) houses three high-speed visible-spectrum cameras arranged concentrically with a separation angle of $36^{\circ}$. As a particle falls through the instrument collection aperture, two vertically spaced infrared detectors simultaneously trigger the cameras to take three simultaneous photographs of the particle from the side and to measure the fall speed between the two detectors. The MASC software processes the imagery to calculate the surface area, geometric cross section, perimeter, orientation, aspect ratio, complexity, flatness, and whether the particle is a raindrop (Shkurko et al., 2016). Images taken by the Multi-Angle Snowflake Camera (MASC) are used in conjunction with the DEID to confirm precipitation type and refine density measurements. A mosaic of MASC images from 5 and 6 February 2020 is shown in Fig. 3. Additional snowflake imagery catalogued from each storm is shown in Appendix C.

\subsection{Particle volume and density}

Immediately following the arrival of a hydrometeor on the plate, the particle cross-sectional area increases rapidly as the hydrometeor adjusts from the ambient air temperature to the temperature of the plate, melting in the process. It reaches a maximum cross-sectional area $A_{\max }$ before shrinking during evaporation. A particle may be melted at the moment that it reaches $A_{\max }$. Nonetheless, due to surface tension, particles that are initially frozen tend to maintain their shape following melting so that $A_{\max }$ is approximately representative of the frozen cross-sectional area in air. In calibration, Singh et al. (2021) found that snowflakes undergo only a $5 \%$ change in $D_{\text {eff }}$ during the melting process.

To obtain an estimate of particle density from particle mass, a spherical volume $V_{\mathrm{S}}$ for each hydrometeor can be estimated from an effective diameter $D_{\text {eff }}$ derived from the $A_{\max } \cdot V_{\mathrm{S}}=\frac{\pi}{6} D_{\text {eff }}^{3}$, where $D_{\text {eff }}=\sqrt{\frac{4}{\pi} A_{\max }}$ (Fig. 4, left). This geometric definition is consistent with that taken by Locatelli and Hobbs (1974), who prescribed $D_{\text {eff }}$ as "the diameter of the smallest circle into which the aggregate as photographed will fit without changing its density". Unless otherwise specified, all instances of "diameter" in the text refer to $D_{\text {eff }}$. An alternative diameter metric is $D_{\max }$ as defined by the circumscribed diameter from the maximum horizontal dimension of the hydrometeor as it lies on the hotplate. The measured relationship between these two metrics is described in Sect. 3.2.

For a more precise estimate of particle volume, sideviewing MASC imagery of hydrometeors can be used to determine the average aspect ratios of hydrometeors measured over a $1 \mathrm{~min}$ time interval. In general, by approximating hydrometeors as an ellipsoid, the volume of a snowflake is $V_{M}=\frac{\pi}{6} D_{\max } D_{\min } D_{\mathrm{v}}$, where $D_{\max }$ is the longest dimension as seen by the DEID, $D_{\min }$ is the shortest, and $D_{\mathrm{v}}$ is bounded by the two. For example, if the hydrometeor shape is an oblate spheroid, then $D_{\mathrm{v}}=D_{\max }$, and if it is a prolate spheroid, then $D_{\mathrm{v}}=D_{\min }$ (Fig. 4, middle). As a snowflake falls onto the plate, the maximum dimension is expected to lie flat with respect to the plate. $D_{\text {eff }}$ is expected to lie between the maximum and minimum dimensions of the snowflake; thus, for the more general case of an ellipsoid, a reasonable assumption is that $D_{v} \simeq D_{\text {eff }}$.

The issue here is that the DEID is unlikely to provide a measure of the minimum dimension. However, it can be reasonably inferred from side views of hydrometeors provided by the multiple concentric images captured by the MASC. For a given snowflake, the minimum of the aspect ratios for each hydrometeor seen by the multiple MASC cameras as captured within a $1 \mathrm{~min}$ interval and subsequently averaged $\alpha_{\text {min }}$ can reveal a characteristic minimum dimension in the vertical direction for the time period that is otherwise invisible to the DEID (Fig. 4, right). Taking $D_{\min }=\alpha_{\min } D_{\max }$, the MASC-adjusted volume is then

$V_{M}=\frac{\pi}{6} D_{\max }^{2} D_{\mathrm{eff}} \alpha_{\min }$

The spherical and mass-adjusted density of individual hydrometeors can then be calculated from the mass $M$ and volume as $\rho_{\mathrm{S}}=M / V_{S}$ and $\rho_{M}=M / V_{M}$ respectively. 
February 5-6, 2020

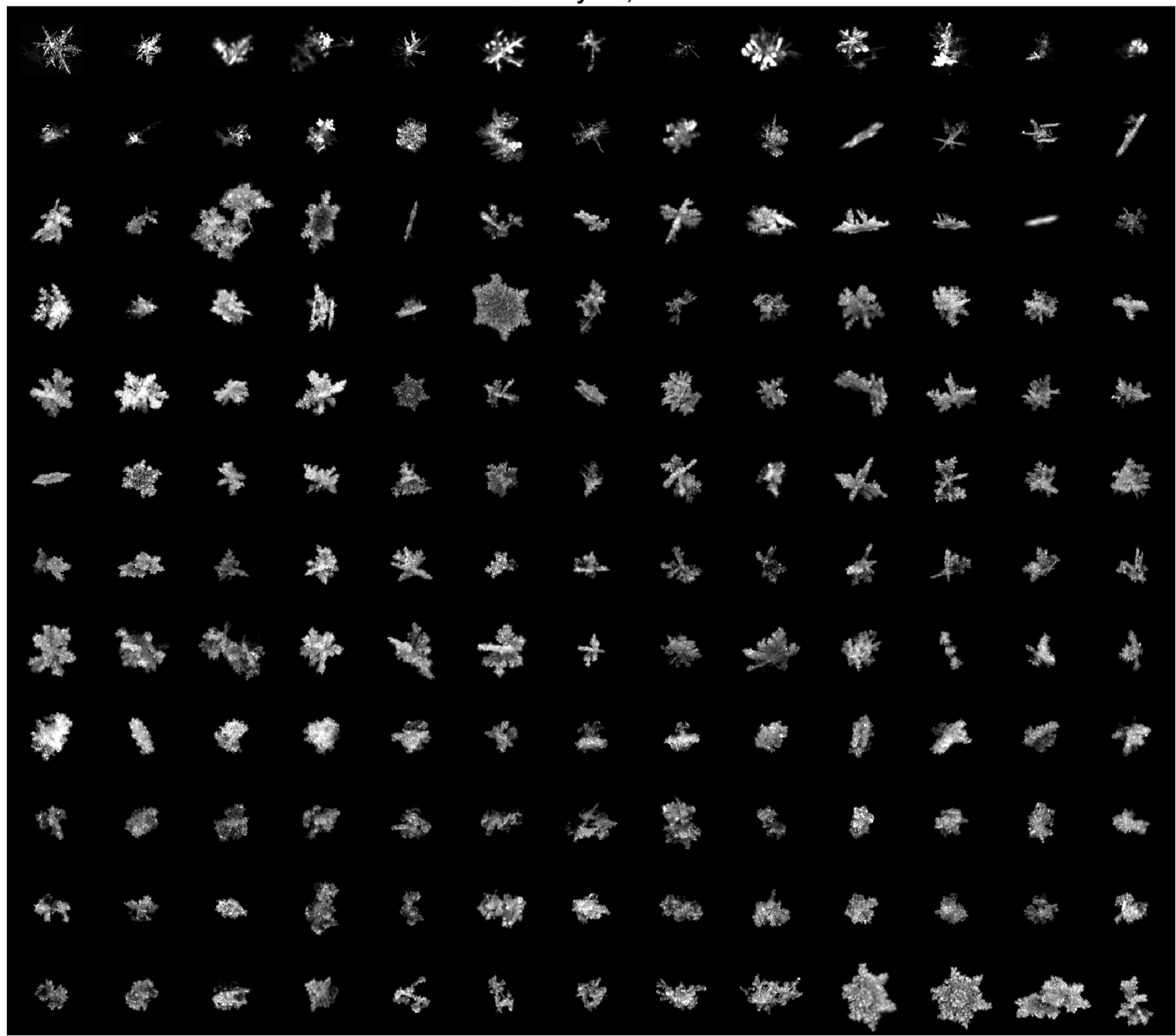

Figure 3. A selection of MASC snowflake images obtained between 5 and 6 February 2020.

\section{Results}

Over the course of five storms that took place in Salt Lake City, Utah, on 14, 17, and 26 January as well as $2-3$ and 5-6 February 2020, the DEID detected 132459 individual hydrometeors. Of those hydrometeors, 104812 were snowflakes, and the remainder were either rain or a rainsnow mix. A filtering algorithm rejected small hydrometeors with fewer than three contiguous pixels of data in all three dimensions (see Appendix B), leaving a total dataset (Rees et al., 2021) of 109316 hydrometeors, of which 86285 were snowflakes and the remainder rain. Of those snowflakes, density estimates for 43649 were obtained using corresponding
MASC imagery. The density of rain of course is known to be $1000 \mathrm{~kg} \mathrm{~m}^{-3}$ and would provide a valuable reference point for this study. Unfortunately, its measurements cannot be addressed using the techniques described here as raindrops do not preserve their area after impaction on the plate.

\subsection{Time series}

Figure 5 shows the mean and the maximum effective diameters of the hydrometeors considered for each 1 min sampling interval. The largest observed maximum diameters occurred during 14 and 26 January, when large aggregates were the primary snow type (see Appendix $\mathrm{C}$ for corresponding snowflake imagery). During such periods characterized pri- 
(a) DEID spherical volume

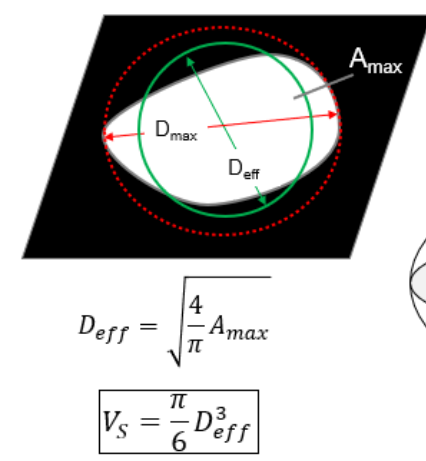

(b) Volume of an ellipsoid

$$
V=\frac{\pi}{6} D_{\max } D_{\min } D_{v}
$$

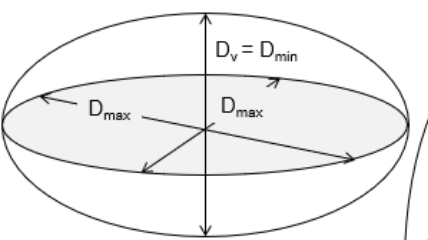

$V=\frac{\pi}{6} D_{\max }^{2} D_{\min }=\frac{\pi}{6} D_{\max }^{2} D_{v}$

$$
D_{\text {min }} \leq D_{v} \leq D_{\text {max }}
$$$$
D_{\min } \leq D_{\text {eff }} \leq D_{\max }
$$

$$
D_{\text {eff }} \simeq D_{v}
$$

(c)

MASC-adjusted volume

Figure 4. Illustration of the diameter and volume calculations by the DEID (a), maximum and minimum theoretical bounds of volume calculations of spheroids (b), and the corresponding volume adjustment using MASC-derived aspect ratio measurements (c).

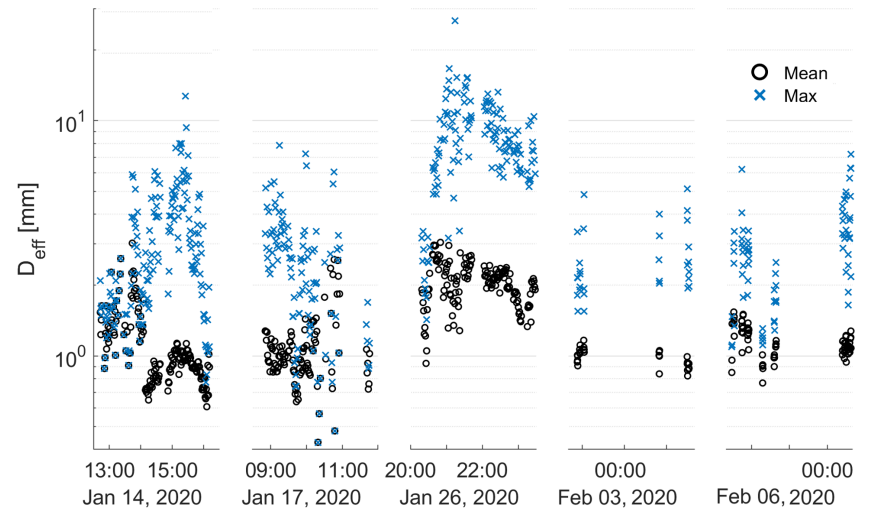

Figure 5. One-minute averaged maximum and mean effective diameters of measured hydrometeors.

marily by aggregate snowflakes, a larger difference was observed between the mean and maximum diameter observed. Periods characterized primarily by graupel, including early 14 and late 17 January, exhibited smaller differences.

Adopting either the spherical volume or the MASCadjusted volume, the probability density functions for $\rho_{\mathrm{S}}$ and $\rho_{M}$ separated by storm and combined for all storms are shown in Fig. 6. Derived density values are approximately log-normally distributed largely ranging between 10 and $100 \mathrm{~kg} \mathrm{~m}^{-3}$. The calculated densities differ by approximately a factor of 2 depending on the calculation method used. For all storms, the mean spherical density was $38 \mathrm{~kg} \mathrm{~m}^{-3}$, and the logarithmically weighted mean was $35 \mathrm{~kg} \mathrm{~m}^{-3}$, while the respective MASC-adjusted density values were 90 and $70 \mathrm{~kg} \mathrm{~m}^{-3}$. The relative absence in the distribution of high- density values derived using the spherical approximation suggests an underestimate given that Locatelli and Hobbs (1974) found lump graupel to have densities ranging as high as $450 \mathrm{~kg} \mathrm{~m}^{-3}$ and dense graupel has also been described by others (Magono and Nakamura, 1965; Holroyd, 1971; Muramoto et al., 1995; Fabry and Szyrmer, 1999; Brandes et al., 2007; Tiira et al., 2016). For example, for the period 14 January 12:43-12:59 MST when MASC imagery showed graupel predominated during a period with temperatures near the melting point, the spherical calculation yielded an average density of $88 \mathrm{~kg} \mathrm{~m}^{-3}$ versus $131 \mathrm{~kg} \mathrm{~m}^{-3}$ for the MASCrelated estimates. The respective logarithmically weighted mean values were 87 and $121 \mathrm{~kg} \mathrm{~m}^{-3}$.

\subsection{Diameter and aspect ratio}

In the following sections, mass-diameter and densitydiameter relationships are expressed with respect to $D_{\text {eff }}$. By way of reference, for the 43649 snowflakes included in this study that are categorized by type, $D_{\max }$ can be correlated with $D_{\text {eff }}$ through the power-law relationship $D_{\max }=a D_{\text {eff }}^{b}$, with values for $a$ and $b$ summarized in Table 1 . In general, the two quantities are highly correlated, and the relationship is nearly linear. For the ensemble taken as a whole, the relationship is $D_{\max }=1.16 D_{\text {eff }}^{1.04}$, with a square correlation coefficient of $R^{2}=0.94$. The average measured aspect ratios seen by the MASC for aggregates, densely rimed particles, and graupel were $0.64,0.65$, and 0.82 respectively. 

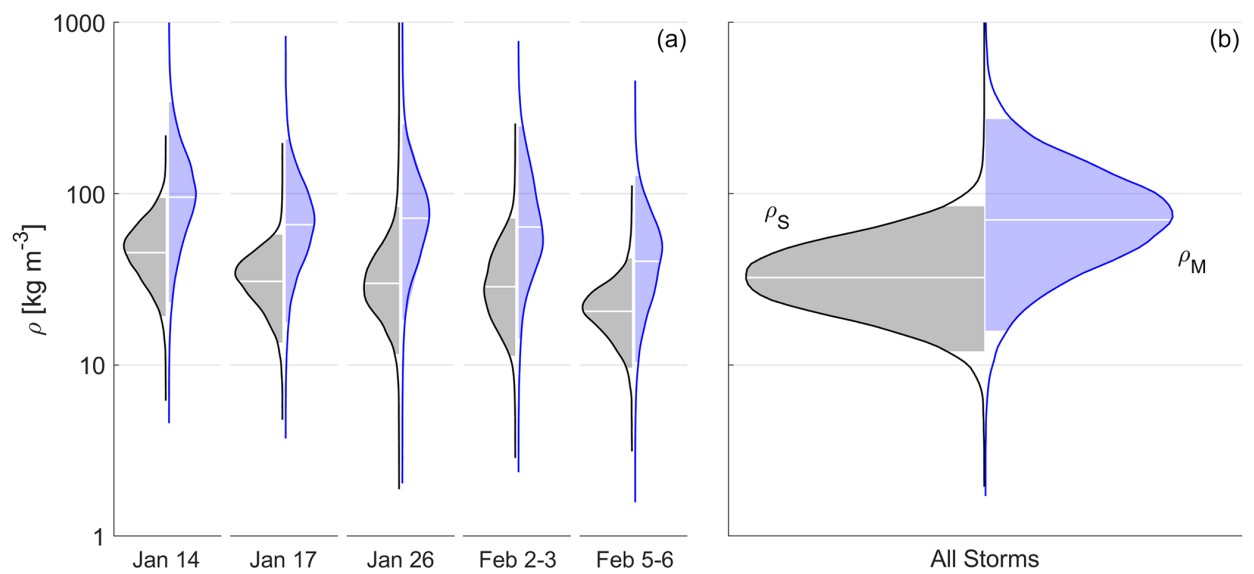

Figure 6. Linear probability density functions of snow density measurements using the spherical volume assumption (gray) and the MASCadjusted volume (blue) separated into individual storms (a) and for all snowflakes (b). Mean values and $\pm 2 \sigma$ values are represented by white horizontal lines and the boundary between shading and white space under the tails of the curves.

Table 1. Relationships between hydrometeor circumscribed and effective diameter.

\begin{tabular}{lrrrr}
\hline \multirow{2}{*}{ Type } & \multicolumn{2}{c}{$D_{\max }=a D_{\text {eff }}^{b}$} & & $*$ \\
\cline { 2 - 3 } & $a$ & $b$ & & \\
\hline All & 1.16 & 1.04 & 0.94 & 43649 \\
Graupel & 1.04 & 1.05 & 0.94 & 34 \\
Densely rimed & 1.16 & 1.04 & 0.94 & 38562 \\
Aggregates & 1.16 & 1.06 & 0.90 & 5053 \\
\hline
\end{tabular}

\subsection{Mass-diameter relationships}

The mass-diameter relationship for all snowflakes is shown in Fig. 7. The prefactor observed in the mass-diameter relationship is 0.018 , which is approximately consistent with the range of values described by Locatelli and Hobbs (1974) for the densely rimed snowflakes (Table 2), comprising $88 \%$ of the snowflakes observed in our study. The exponent 2.52, however, generally exceeds those values obtained by Locatelli and Hobbs (1974) for graupel-like (2.1 to 2.4), densely rimed (2.1 to 2.3), and aggregated (1.4 to 1.9) snow.

Snowflakes were selected manually through visual classification using MASC imagery for time periods at least 3 min long where no other snow types were present, defined as aggregates $(N=5053)$, graupel $(N=34)$, and densely rimed $(N=38562)$. The densely rimed category includes all snowflakes not categorized as graupel or aggregates following Garrett and Yuter (2014). It also includes densely rimed aggregates and partially melted aggregates. Figures 3 and $\mathrm{C} 1-\mathrm{C} 4$ show mostly planar type crystals present, but aggregated needles are frequently seen as well. Graupel occurred frequently, although there was only one $16 \mathrm{~min}$ long period that did not exhibit any other type of snow. Massdiameter relationships $M=a D_{\mathrm{eff}}^{b}$ for graupel, densely rimed

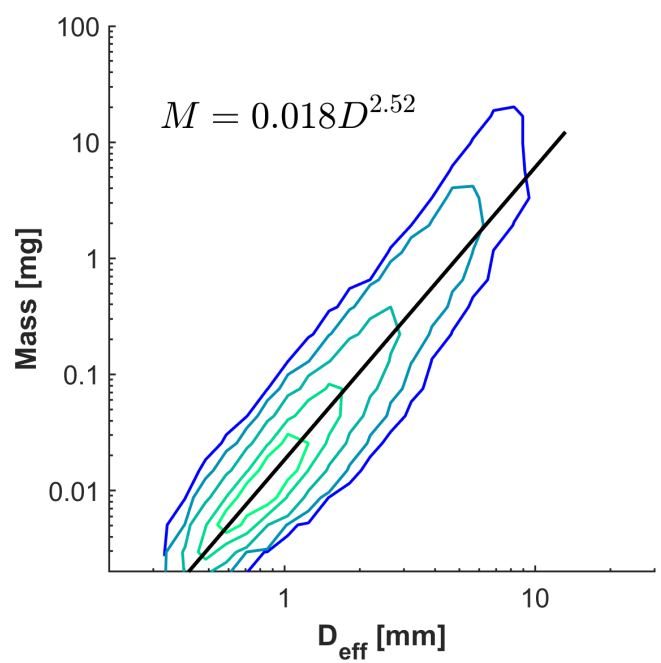

Figure 7. Mass-diameter relationship for all 86285 snowflakes. Contours shown are for the $25 \mathrm{th}, 50 \mathrm{th}, 75 \mathrm{th}, 90 \mathrm{th}$, and 95 th percentiles.

snow, and aggregates are compared with those found by (Locatelli and Hobbs, 1974) in Fig. 8 and Table 2. Values of $a$ and $b$ for graupel determined by the DEID $(a=0.047$ and $b=2.73$ ) lie within the ranges observed by Locatelli and Hobbs (1974): $0.042<a<0.140$ and $2.6<b<3.0$. The quantity of densely rimed and aggregate snowflakes collected by the DEID was roughly 5 orders more numerous than those described by Locatelli and Hobbs (1974). For densely rimed snowflakes, the prefactor $a$ lies within the range observed by Locatelli and Hobbs (1974), and the exponent $b$ is within $11 \%$. Aggregate snowflakes differ by $12 \%$ in the exponent and by $38 \%$ in the prefactor. In contrast to the findings of Erfani and Mitchell (2017), which state that particle riming changes the prefactor $a$ but not $b$, here both $a$ and $b$ decrease with increased riming. 

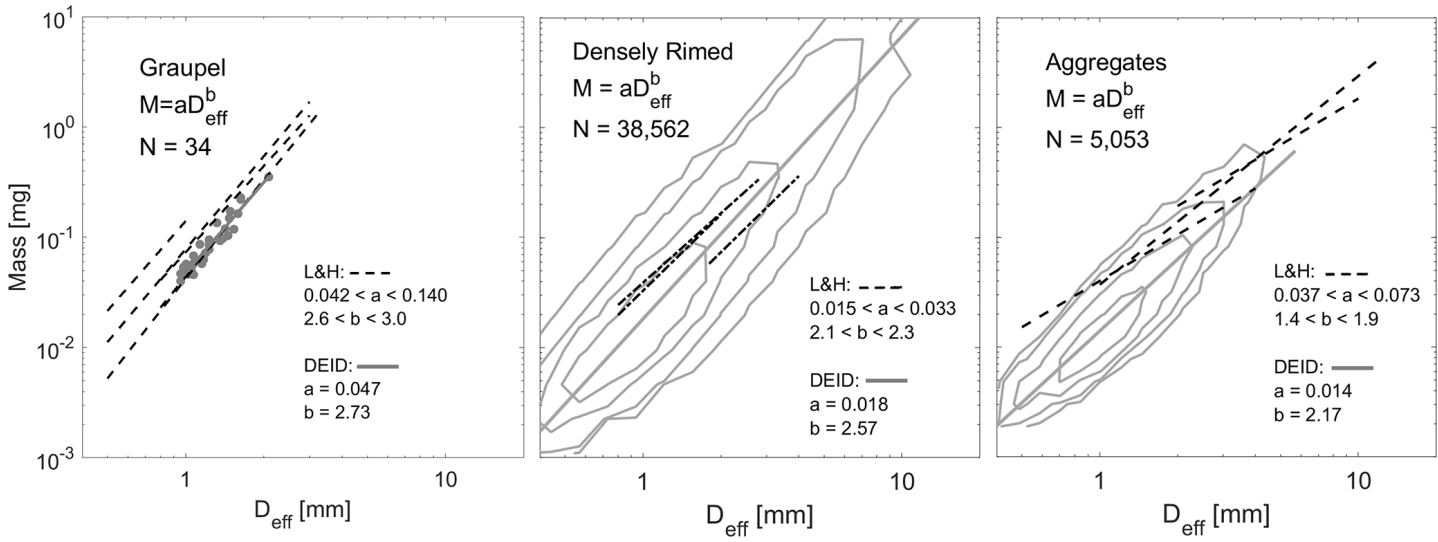

Figure 8. Mass-diameter relationships from the DEID (solid lines) sorted by type according to MASC imagery and compared with fits from Locatelli and Hobbs (1974), dashed lines. Contours are for 50th, 75th, 90th, and 95th percentile bounds.

Figure 9 illustrates the sensitivity of mass-diameter relationship parameters to particle type and ambient air temperature. Garrett and Yuter (2014) employed the MASC-derived complexity parameter, $\chi=P(1+<\sigma>) /(2 r)$, where $P$ is the snowflake perimeter, $r$ is the snowflake radius, and $\langle\sigma\rangle$ is the intensity variability, to classify snowflakes into three categories: graupel $(\chi<1.35)$, densely rimed $(1.35 \leq \chi \leq$ $1.75)$, and aggregates $(\chi>1.75)$. Threshold values of 1.3 and 1.8 have also been previously used (Garrett et al., 2015). Here we adopt threshold values of 1.3 and 1.7. Graupellike snow is included in the graupel category; the two data points with $\chi<1.3$ include 9506 snowflakes, which are unlikely to be solely graupel due to $1 \mathrm{~min}$ averaging of $\chi$ and the presence of other snow types observed during graupel events. This category has values of $b$ consistent with the exponent values between 2.1 and 2.4 found by Locatelli and Hobbs (1974). The densely rimed category, however, has exponent values between 2.5 and 2.7, which are higher than those seen by Locatelli and Hobbs (1974), although the difference may be influenced by presence of a large number of partially melted snowflakes that bring the exponent closer to 3. Overall, smaller values of $b$ are obtained as $\chi$ exceeds 1.7 and snowflakes transition into aggregates. Notably, the value of $b$ is never lower than 2 .

Partially melted snowflakes are excluded favoring more aggregate type snowflakes by restricting analysis to particles that fell when the ambient air temperature was $<-3{ }^{\circ} \mathrm{C}$, as represented by blue lines in Fig. 9. There is a clear sensitivity in the mass-diameter relationships to ambient air temperature. For all snowflakes that occurred when the ambient air temperature was $<0^{\circ} \mathrm{C}(N=30651)$, the values of $a$ and $b$ are 0.017 and 2.33, respectively, with $R^{2}=0.85$. For all snowflakes that fell when the ambient air temperature was $<-3{ }^{\circ} \mathrm{C}(N=4630)$, the corresponding values are 0.015 and 2.12 , with $R^{2}=0.84$.

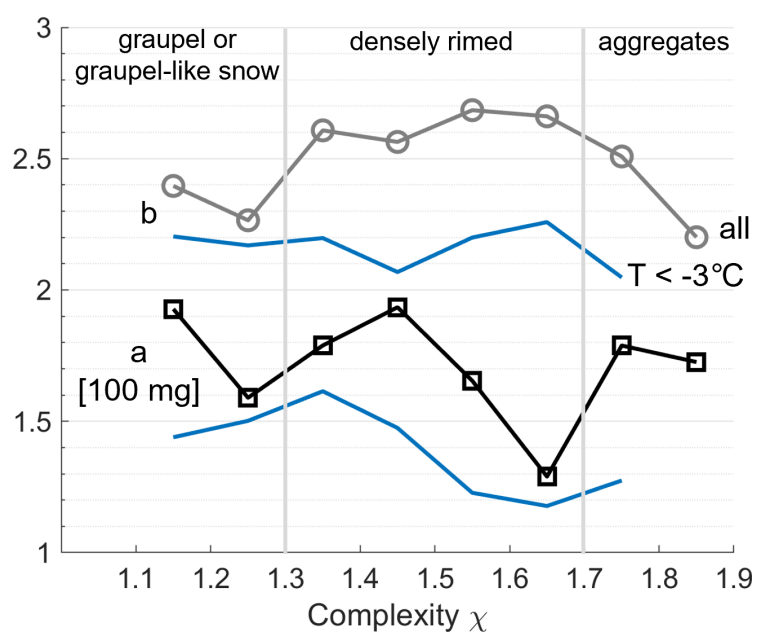

Figure 9. Exponent (gray) and prefactor (black) values in the massdiameter relationship as binned by 1 min average particle complexity and filtered by ambient temperature (blue line).

\subsection{Density-diameter relationship}

Density-diameter relationships for all snowflakes in this study are shown in Fig. 10, and a comparison of densitydiameter relationships from this work and prior studies is shown in Fig. 11. Using the spherical volume approximation (Fig. 10, left), the measured values for density are rarely greater than $100 \mathrm{~kg} \mathrm{~m}^{-3}$, suggesting a possible underestimate. Using a similar assumption, Muramoto et al. (1995) observed similarly low values of density (Fig. 11). The density-diameter relationships from other studies shown in Fig. 11 include both dry and wet snowflakes and ice particles with densities extending into the $200-300 \mathrm{~kg} \mathrm{~m}^{-3}$ range for the lowest diameters observed.

More refined density calculations supplemented by MASC data are shown in Fig. 10, right, and include high values near the density of bulk water, as would be expected for wet 
Table 2. Mass-diameter relationship comparison by type.

\begin{tabular}{|c|c|c|c|c|c|c|c|c|}
\hline \multirow{3}{*}{ Type } & \multicolumn{4}{|c|}{ Locatelli and Hobbs (1974) } & \multicolumn{4}{|c|}{ DEID } \\
\hline & \multicolumn{2}{|c|}{$M=a D^{b}$} & \multirow[t]{2}{*}{$R^{2}$} & \multirow[t]{2}{*}{$N$} & \multicolumn{2}{|c|}{$M=a D^{b}$} & \multirow[t]{2}{*}{$R^{2}$} & \multirow[t]{2}{*}{$N$} \\
\hline & $a$ & $b$ & & & $a$ & $b$ & & \\
\hline Graupel & $0.042-0.140$ & $2.6-3.0$ & $0.91-0.98$ & $17-58$ & 0.047 & 2.73 & 0.92 & 34 \\
\hline Graupel-like snow & $0.021-0.059$ & $2.1-2.4$ & $0.72-0.91$ & $17-31$ & & & & \\
\hline Densely rimed & $0.015-0.033$ & $2.1-2.3$ & $0.78-0.92$ & $9-13$ & 0.018 & 2.57 & 0.91 & 38562 \\
\hline Aggregates & $0.037-0.073$ & $1.4-1.9$ & $0.78-0.91$ & $19-27$ & 0.014 & 2.17 & 0.85 & 5053 \\
\hline
\end{tabular}

Mass-diameter relationship $M=a D^{b}$, where mass is in milligrams and diameter is in millimeters.

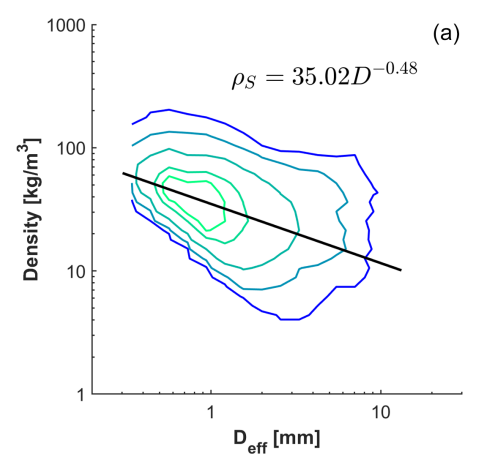

(a)

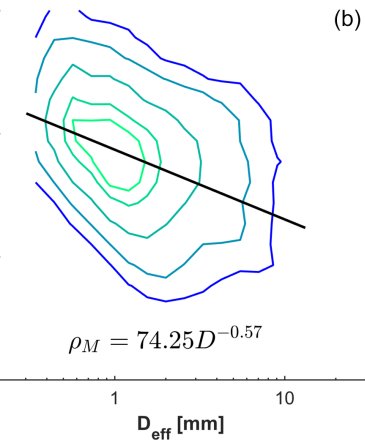

Figure 10. Density-diameter relationships for spherical (a) and MASC-adjusted (b) volume for all snowflakes. Contours shown are for the 25th, 50th, 75th, 90th, and 95th percentiles.

Table 3. Density-diameter relationship comparison by ambient air temperature.

\begin{tabular}{llrrrr}
\hline \multirow{2}{*}{ Density } & \multirow{2}{*}{ Ambient } & \multicolumn{2}{c}{$\rho=a D^{b}$} & $R^{2}$ & $N$ \\
\cline { 3 - 4 } method & $T\left({ }^{\circ} \mathrm{C}\right)$ & $a$ & $b$ & & \\
\hline Spherical & All & 35.05 & -0.48 & 0.24 & 86285 \\
Spherical & $<0$ & 34.87 & -0.56 & 0.27 & 72944 \\
Spherical & $<-3$ & 28.12 & -0.91 & 0.50 & 5042 \\
MASC & All & 74.25 & -0.57 & 0.17 & 43649 \\
MASC & $<0$ & 67.27 & -0.91 & 0.27 & 30651 \\
MASC & $<-3$ & 53.64 & -1.28 & 0.35 & 4630 \\
\hline
\end{tabular}

snowflakes that have partially melted before reaching the hotplate. The prefactors $a$ are 35.02 and 74.25 for the spherical and MASC-adjusted density respectively, and the exponents $b$ are -0.48 and -0.57 . The values of $a$ and $b$ were also obtained when filtering snowflakes by temperature to exclude partially melted snowflakes $\left(T<0^{\circ} \mathrm{C}\right)$ and to reflect primarily aggregate snowflakes $\left(T<-3^{\circ} \mathrm{C}\right)$, and they are shown in Table 3.

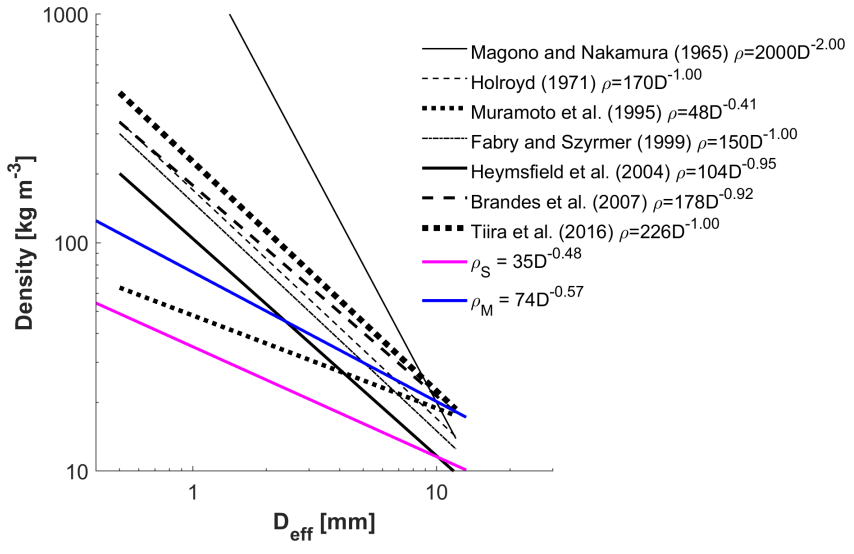

Figure 11. Density-diameter relationships from previous studies and those obtained here using the spherical density method (magenta) and MASC-adjusted density method (blue).

\section{Discussion}

A notable difference between the mass-diameter relationships from our study versus those described previously by Locatelli and Hobbs (1974) lies in fitted exponents for both densely rimed and aggregate type snowflakes. In the earlier study these ranged from 2.1 to 2.3 for densely rimed and 1.4 to 1.9 for aggregates, while our results point to exponents of 2.57 and 2.17. An added implication of the larger exponents is that the masses of very small aggregates with diameters less than $1 \mathrm{~mm}$ are generally smaller than have previously been reported (Fig. 8). While the MASC-adjusted density-diameter relationships align closely with several previous studies (Fig. 11) for particle sizes larger than approximately $5 \mathrm{~mm}$ diameter, much lower values of density tend to be observed at smaller particle sizes. Where the exponents described in previous studies (Holroyd, 1971; Fabry and Szyrmer, 1999; Heymsfield, 2003; Brandes et al., 2007; Tiira et al., 2016) are close to -1 , those from our study are approximately -0.5 , suggesting a weaker dependence of density on particle size than is generally assumed, especially at ambient air temperatures near $0{ }^{\circ} \mathrm{C}$. However, by excluding higher temperatures near freezing to omit partially 
melted snowflakes, the exponents more closely approach -1 . The average density of all hydrometeors using the spherical volume assumption is 38 and $90 \mathrm{~kg} \mathrm{~m}^{-3}$ using the MASCadjusted volume. For comparison, the density of snowfall on the ground at a high-elevation location in the Wasatch Mountains in Utah is typically less than $100 \mathrm{~kg} \mathrm{~m}^{-3}$ (Alcott and Steenburgh, 2010), a location where mode snowflake diameters lie between 1 and $2 \mathrm{~mm}$ (Garrett and Yuter, 2014).

\section{Summary}

We describe measurements of the mass and density of individual frozen hydrometeors obtained using a new instrument, the Differential Emissivity Imaging Disdrometer. Powerlaw mass-diameter relationships obtained by the DEID derived from 86285 measured particles agree well with widely used relationships published by Locatelli and Hobbs (1974), which were based on a much more limited dataset. The exception is that snowflakes measured by the DEID have exponents higher by between $12 \%$ and $38 \%$. To obtain hydrometeor density from the measured mass, estimates of volume are required. Here, a simple spherical approximation for particle volume based on the particle equivalent diameter seen by a thermal camera viewing the heated plate led to density estimates approximately a factor of 2 lower than those using a more refined calculation that incorporated concurrent MASC measurements of the particle aspect ratio. For the subset of DEID measurements that included coincident MASC imagery totaling 43649 hydrometeors, the resulting densitydiameter relationships suggest substantially lower densities of particles smaller than $5 \mathrm{~mm}$ than has been observed in most prior studies. It may be that existing bulk microphysical parameterizations in numerical weather models tend to underestimate the masses of large frozen hydrometeors while overestimating those of smaller hydrometeors. If true, any revision could have possible implications for forecasts of snow water deposition in mountain reservoirs. Future anticipated refinements to the DEID particle volume algorithm at a wider range of locations may help further refine estimates of hydrometeor density. 


\section{Appendix A: Hotplate calibration}

The constant $K_{\mathrm{d}}$, which includes the specific heat capacity, equivalent latent heat, and the plate's thickness and thermal conductivity, was calibrated experimentally for the DEID aluminum plate (Singh et al., 2021). The plate was roughened with 600-grit (P1200) sandpaper to allow for droplet spreading and more rapid evaporation of water during calibration experiments. Water drops of known masses were evaporated on the plate to determine the calibrated coefficient. Combining the constants in Eq. (1) yields

$\left(c_{p} \Delta T_{\mathrm{ev}}+L_{\mathrm{v}}\right) M=\frac{K}{H} \int_{0}^{t} A(t)\left(T_{\mathrm{p}}-T_{\mathrm{w}}(t)\right) \mathrm{d} t$,

where $M$ is a known mass of water. A constant is determined that includes the thermal conductivity and the thickness of the hotplate using droplets of known mass $M=2 \pm 0.2 \times$ $10^{-5} \mathrm{~kg}$ :

$\frac{K}{H}=\frac{M\left(c_{p, \mathrm{w}} \Delta T_{\mathrm{ev}}+L_{\mathrm{v}}\right)}{\int_{0}^{t} A(t) T_{\mathrm{p}}-T_{\mathrm{w}}(t) \mathrm{d} t}$,

where $\int_{0}^{t} T_{\mathrm{p}}-T_{\mathrm{w}}(t) A(t) \mathrm{d} t$ was determined from DEID measurements, $c_{p, \mathrm{w}}=4.28 \times 10^{3} \mathrm{~J} \mathrm{~K}^{-1} \mathrm{~kg}^{-1}$ is the specific heat of water at constant pressure, $\Delta T_{\mathrm{ev}}=100 \mathrm{~K}$, and $L_{\mathrm{v}}=2.26 \times 10^{6} \mathrm{~J} \mathrm{~kg}^{-1}$ is the latent heat of vaporization. Determined through 10 trials, $K / H=4.1 \pm 0.1603 \times$ $10^{3} \mathrm{~kg} \mathrm{~s}^{-3} \mathrm{~K}^{-1}$.

Including the latent and specific heat required to evaporate liquid water and ice, respectively, the derived values of $K_{\mathrm{d}}$ for liquid and ice are then

$$
\begin{aligned}
K_{\mathrm{d}, 1}= & \frac{K / H}{\left(c_{p, \mathrm{w}} \Delta T_{\mathrm{ev}}+L_{\mathrm{v}}\right)}=\frac{4.1 \times 10^{3}}{2.67 \times 10^{6}}= \\
& 1.54 \times 10^{-3}\left[\frac{\mathrm{kg}}{\mathrm{s} \mathrm{K} \mathrm{m}^{2}}\right], \\
K_{\mathrm{d}, \mathrm{i}}= & \frac{K / H}{\left(c_{p, \mathrm{w}} \Delta T_{\mathrm{ev}}+L_{\mathrm{v}}+c_{p, \mathrm{i}} \Delta T_{m}+L_{\mathrm{f}}\right)}= \\
& \frac{4.1 \times 10^{3}}{3.03 \times 10^{6}}=1.35 \times 10^{-3}\left[\frac{\mathrm{kg}}{\mathrm{s} \mathrm{K} \mathrm{m}^{2}}\right],
\end{aligned}
$$

where $c_{p, \mathrm{i}}=2.10 \times 10^{3} \mathrm{~J} \mathrm{~K}^{-1} \mathrm{~kg}^{-1}$ is the specific heat of ice at constant pressure and the latent heat of fusion $L_{\mathrm{f}}=$ $3.34 \times 10^{5} \mathrm{~J} \mathrm{~kg}^{-1}$. The equation for mass becomes $M=$ $K_{\mathrm{d}} \int_{0}^{t} A(t)\left(T_{\mathrm{p}}-T_{\mathrm{w}}(t)\right) \mathrm{d} t$.

Experiments comparing mass calculations using $\int_{0}^{t} A(t) T_{\mathrm{p}}-T_{\mathrm{w}}(t) \mathrm{d} t$ and $\Delta T \int_{0}^{t} A \mathrm{~d} t$, where $\Delta T=T_{\mathrm{p}}-T_{\mathrm{w}}(t)$ is the mean value per particle, showed that the latter is a sufficient approximation and the equation for mass may then be expressed as

$M=K_{\mathrm{d}} \Delta T \int_{0}^{t} A(t) \mathrm{d} t$. 


\section{Appendix B: Image processing}

The MATLAB Image Processing Toolbox was used to extract data from the thermal camera to determine the physical properties of individual melted hydrometeors. Experimentally relevant parameters include the hotplate temperature $T_{\mathrm{p}}$, the sampling frequency of the thermal camera $f_{\mathrm{s}}$, the physical width of each pixel in the camera imagery $p$, and the sampling area of the hotplate $A_{\text {hot }}$. Each thermal camera image was converted to both grayscale and binary format. Three-dimensional volumetric regions, "voxels", in a product space of hydrometeor area on the DEID plate and time during the duration of the melting of each particle were evaluated to yield the particle mass through Eq. (A5), as illustrated in Figs. B1-B5.

For the sake of processing, all partial voxel objects that bordered the edge of the 3D sampling area were removed for individual particle calculations. A filtering threshold was used to remove small particles with fewer than three pixel data points in any dimension.

The temperature difference between the hotplate and water $\left(\Delta T=T_{\mathrm{p}}-T_{\mathrm{w}}(t)\right)$ is based on the mean pixel intensity of the particle during its lifetime on the hotplate. The mean pixel intensity $I_{\text {mean }}$ is converted to $\Delta T$ through the linear transformation $\left(\left(T_{\mathrm{p}}-T_{\mathrm{w}}(t)\right) \approx \Delta T=T_{\mathrm{p}}\left(255-I_{\text {mean }}\right) / 256\right)$.

The integrated cross-sectional area of the particle during its evaporation time on the hotplate is given by $V_{t}=$ $\int A(t) \mathrm{d} t$. The effective diameter $D_{\text {eff }}$ is calculated from the point in time associated with the maximum recorded cross-sectional area of the particle $A_{\max }$ according to $D_{\text {eff }}=$ $\sqrt{\frac{4}{\pi} A_{\max }}$. The evaporation time of each particle is calculated by generating a bounding box, or the smallest box that contains the $3 \mathrm{D}$ region containing $V_{t}$, where the circumscribed diameter $D_{\max }$ is the maximum in the area dimension and the evaporation time $t_{\text {evap }}$ is the maximum in the time dimension.

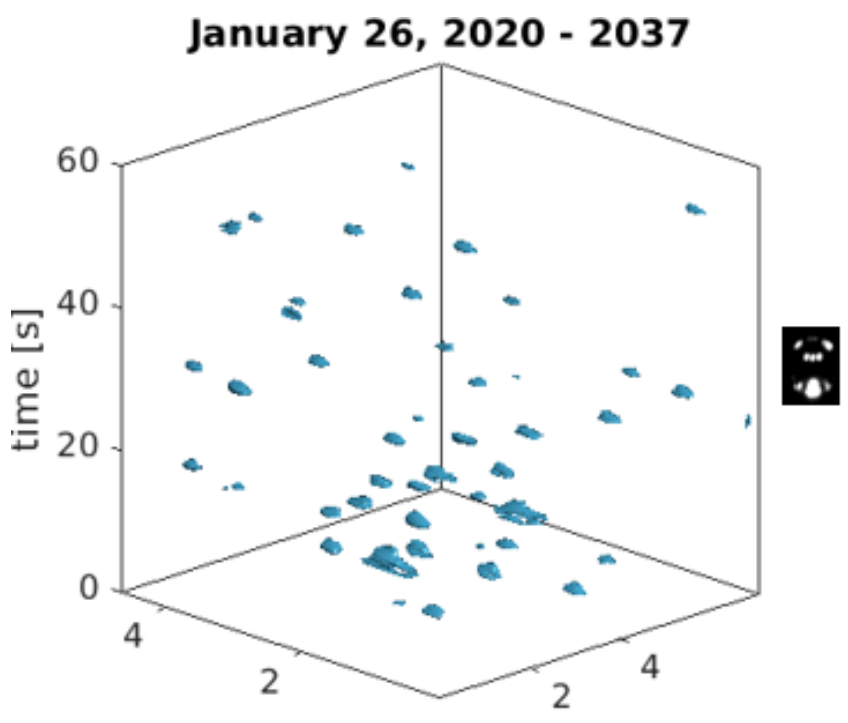

Hotplate [cm]

Hotplate [cm]

Figure B1. Volumetric rendering of melting rain hydrometeors in area on the DEID plate and in time such that each isosurface represents a rain drop frozen at a point in time.

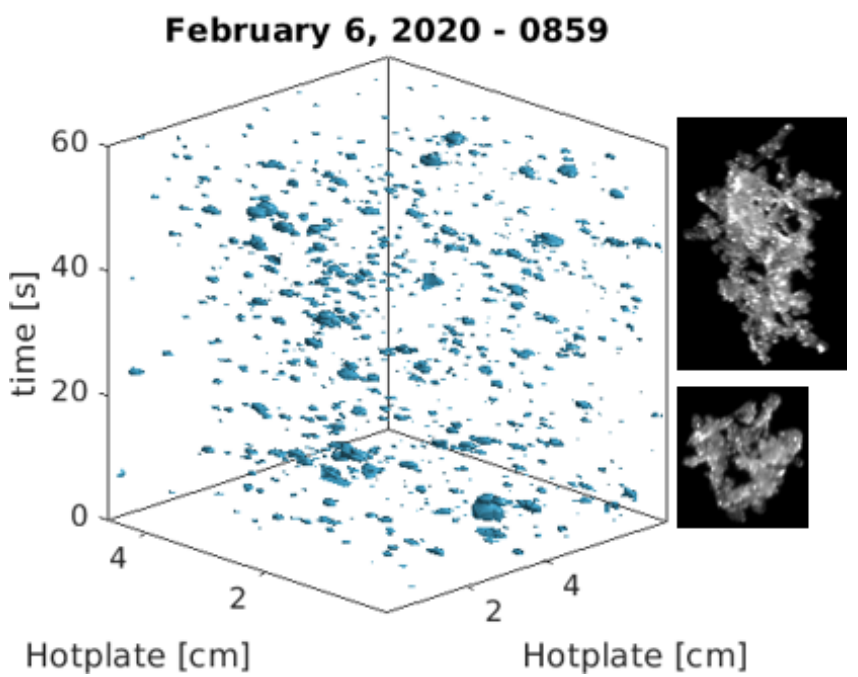

Figure B2. As for Fig. B1 but for partly melted hydrometeors. 


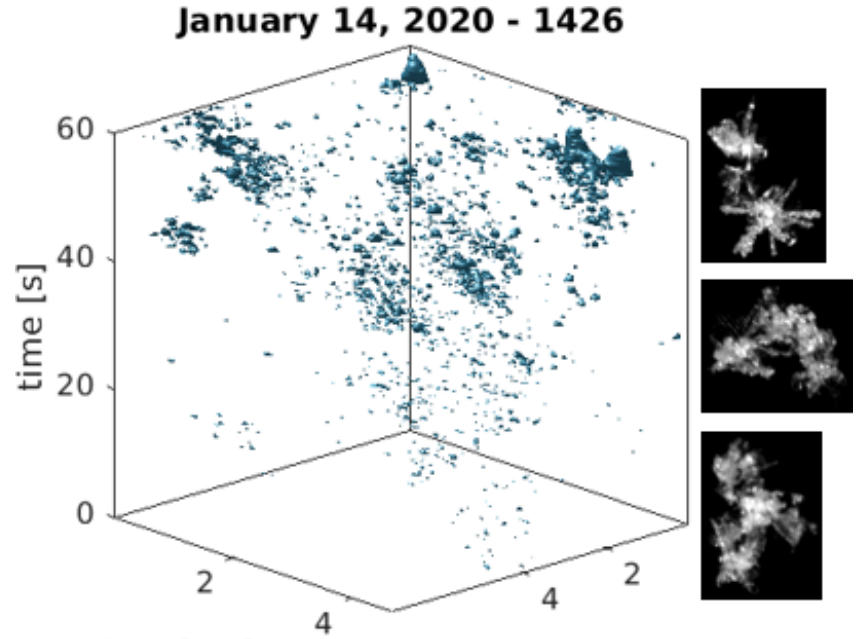

Hotplate $[\mathrm{cm}]$

Hotplate $[\mathrm{cm}]$

Figure B3. As for Fig. B1 but for aggregate snow.

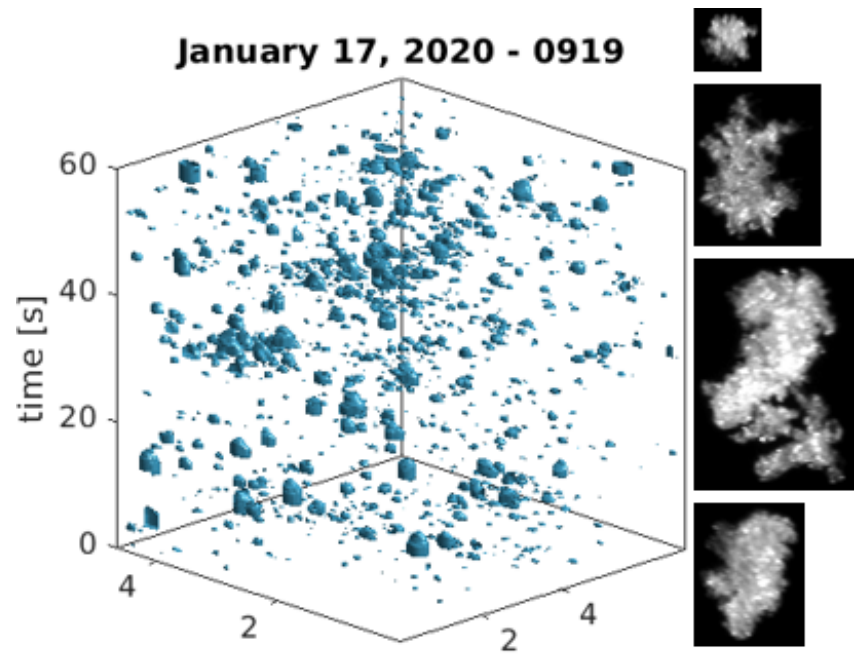

Hotplate $[\mathrm{cm}]$

Hotplate [cm]

Figure B4. As for Fig. B1 but for densely rimed aggregate snow.

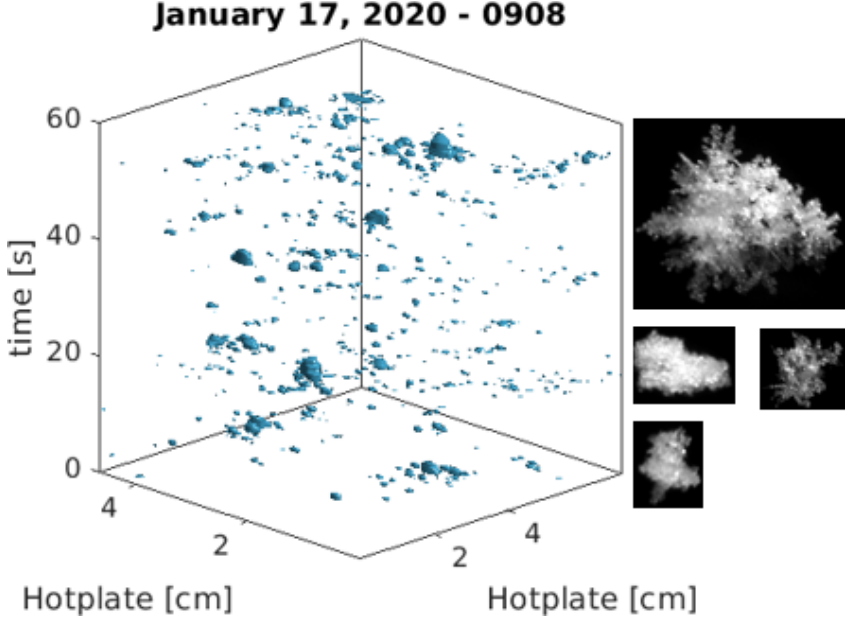

Figure B5. As for Fig. B1 but for a mixture of densely rimed and aggregate snow. 


\section{Appendix C: MASC snowflake imagery}

MASC imagery of frozen hydrometeors was catalogued for each snow event described in this article with representative particles shown in Figs. $\mathrm{C} 1$ to $\mathrm{C} 4$.

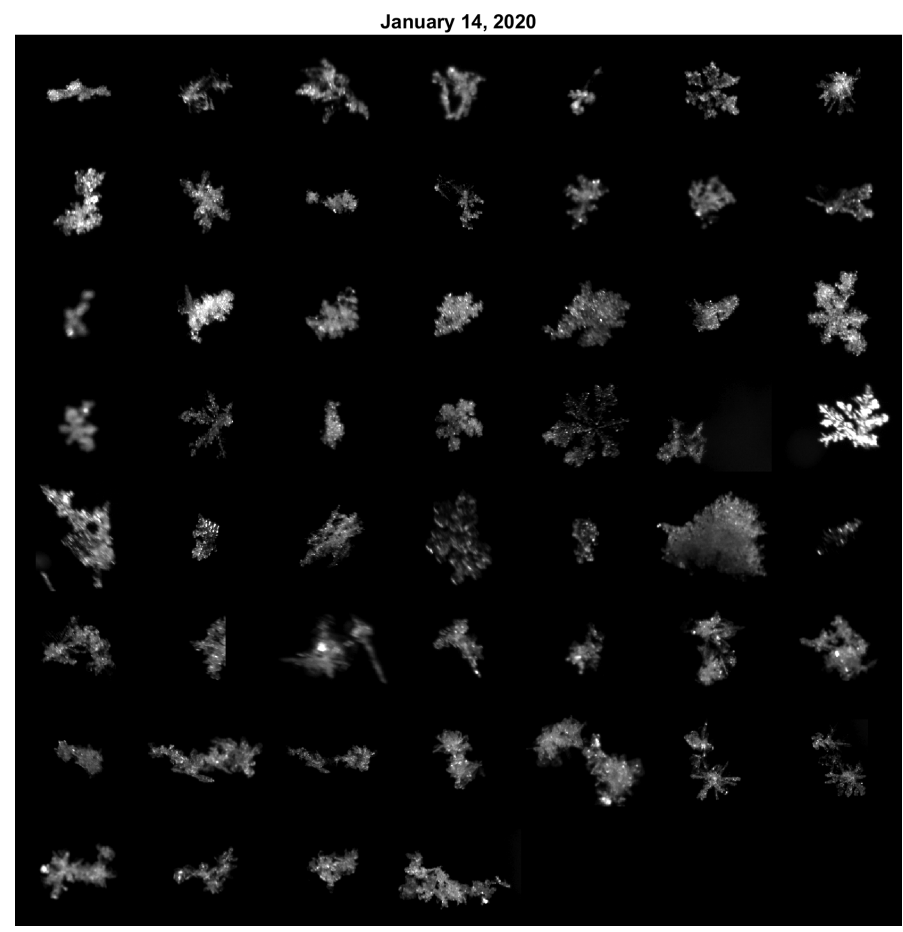

Figure C1. MASC snowflake imagery for 14 January 2020.

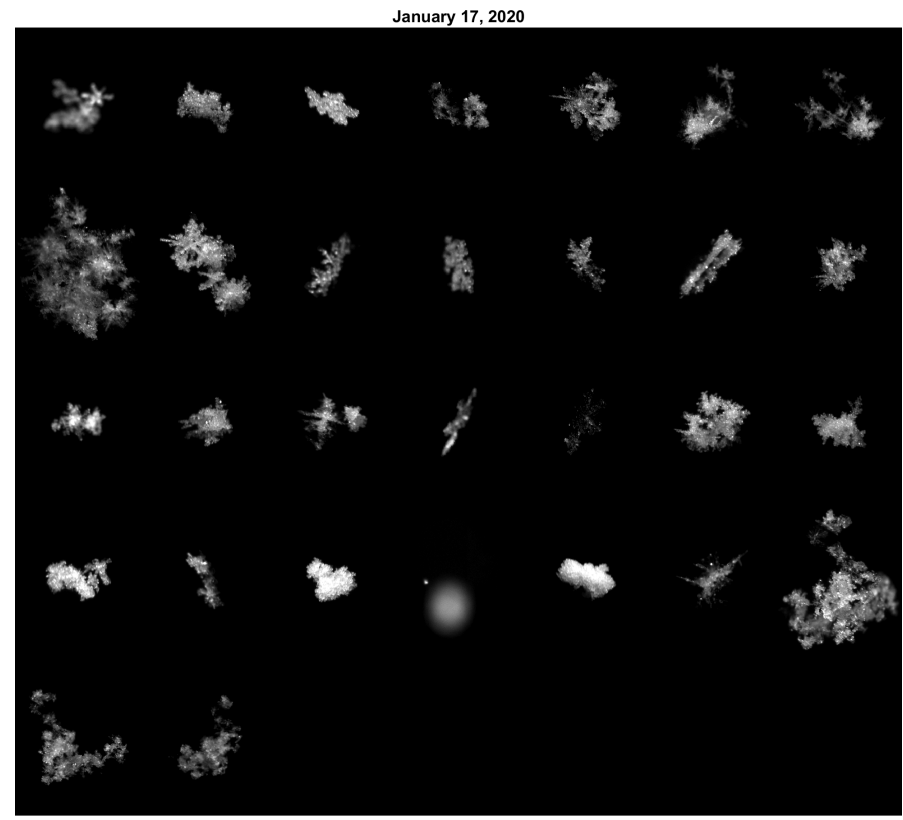

Figure C2. MASC snowflake imagery for 17 January 2020. 
January 26, 2020

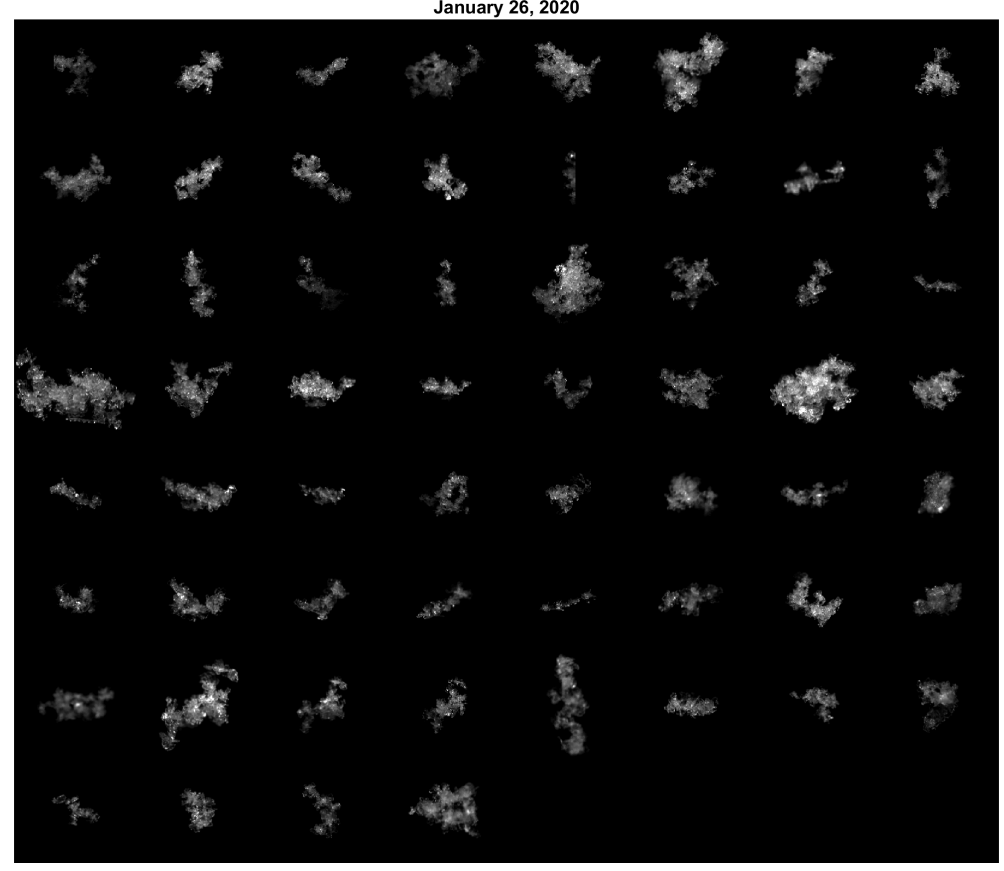

Figure C3. MASC snowflake imagery for 26 January 2020.

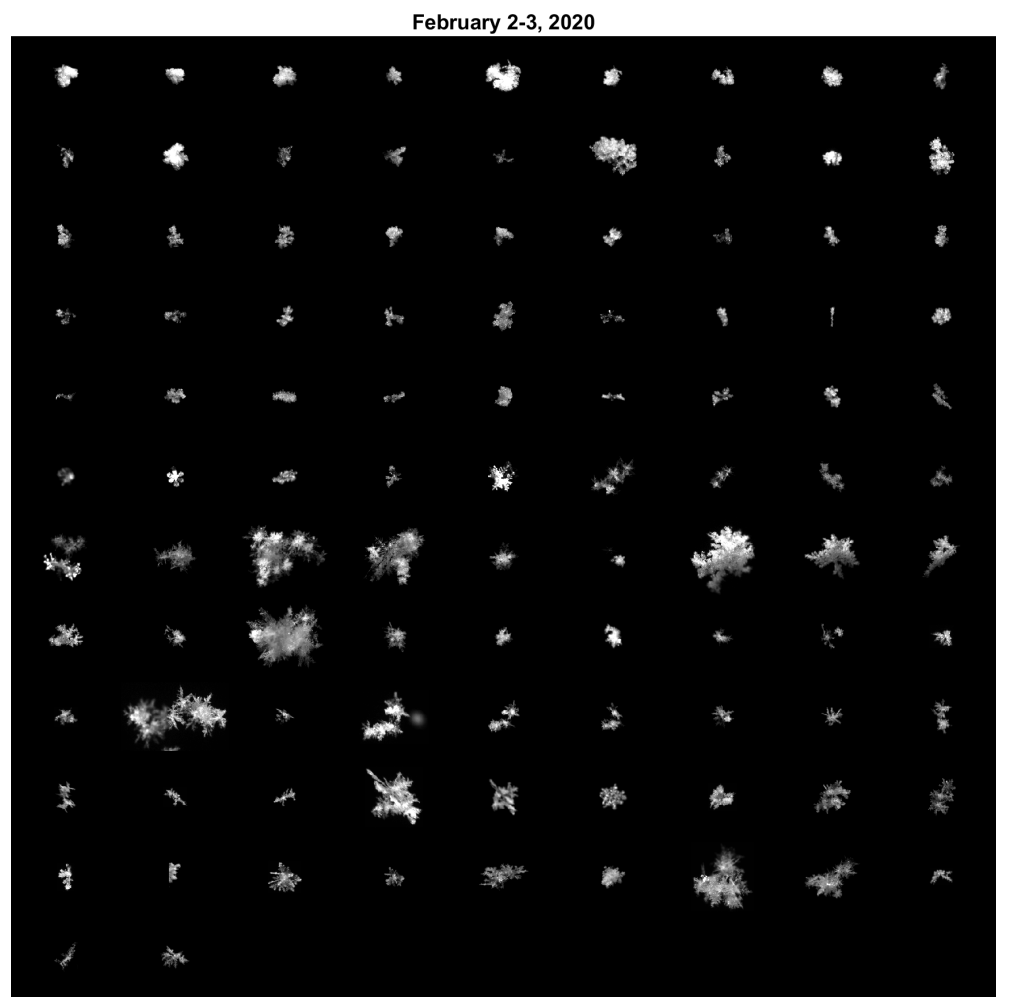

Figure C4. MASC imagery for 2 to 3 February 2020. 
Data availability. The dataset used in this work can be accessed at https://doi.org/10.7278/S50D-SPT1-FNHH (Rees et al., 2021).

Author contributions. TJG and ERP conceived of the project. KNR and DKS led collection and analysis of the data. KNR and TJG contributed equally to writing the manuscript with contributions from ERP.

Competing interests. The DEID is protected through patent US20210172855A1, co-authored by Karlie N. Rees, Dhiraj K. Singh, Eric R. Pardyjak, and Timothy J. Garrett. Timothy J. Garrett is a co-owner of Particle Flux Analytics, Inc., which has a license from the University of Utah to commercialize the DEID. Some authors are members of the editorial board of Atmospheric Chemistry and Physics. The peer-review process was guided by an independent editor.

Disclaimer. Publisher's note: Copernicus Publications remains neutral with regard to jurisdictional claims in published maps and institutional affiliations.

Acknowledgements. We are grateful to David Mitchell and an anonymous reviewer for comments as well as to Spencer Donovan and Allan Reaburn and colleagues at Particle Flux Analytics for their contributions to the field program and the development of the DEID.

Financial support. This research has been supported by the National Science Foundation (grant no. 1841870) and the Department of Energy, Labor and Economic Growth (grant no. DESC0016282).

Review statement. This paper was edited by Barbara Ervens and reviewed by David Mitchell and one anonymous referee.

\section{References}

Alcott, T. I. and Steenburgh, W. J.: Snow-to-liquid ratio variability and prediction at a high-elevation site in Utah's Wasatch Mountains, Weather Forecast., 25, 323-337, 2010.

Barthazy, E. and Schefold, R.: Fall velocity of snowflakes of different riming degree and crystal types, Atmos. Res., 82, 391-398, 2006.

Barthazy, E., Göke, S., Schefold, R., and Högl, D.: An Optical Array Instrument for Shape and Fall Velocity Measurements of Hydrometeors, J. Atmos. Ocean. Tech., 21, 1400-1416, https://doi.org/10.1175/15200426(2004)021<1400:AOAIFS>2.0.CO;2, 2004.

Battaglia, A., Rustemeier, E., Tokay, A., Blahak, U., and Simmer, C.: PARSIVEL Snow Observations: A Crit- ical Assessment, J. Atmos. Ocean. Tech., 27, 333-344, https://doi.org/10.1175/2009JTECHA1332.1, 2010.

Böhm, H. P.: A General Equation for the Terminal Fall Speed of Solid Hydrometeors, J. Atmos. Sci., 46, 2419-2427, https://doi.org/10.1175/15200469(1989)046<2419:AGEFTT>2.0.CO;2, 1989.

Brandes, E. A., Ikeda, K., Zhang, G., Schönhuber, M., and Rasmussen, R. M.: A Statistical and Physical Description of Hydrometeor Distributions in Colorado Snowstorms Using a Video Disdrometer, J. Appl. Meteorol. Clim., 46, 634-650, https://doi.org/10.1175/JAM2489.1, 2007.

Brandes, E. A., Ikeda, K., Thompson, G., and Schönhuber, M.: Aggregate Terminal Velocity/Temperature Relations, J. Appl. Meteorol. Clim., 47, 2729-2736, https://doi.org/10.1175/2008JAMC1869.1, 2008.

Brun, E., David, P., Sudul, M., and Brunot, G.: A numerical model to simulate snow-cover stratigraphy for operational avalanche forecasting, J. Glaciol., 38, 13-22, https://doi.org/10.3189/S0022143000009552, 1992.

Colle, B. A., Garvert, M. F., Wolfe, J. B., Mass, C. F., and Woods, C. P.: The 1314 December 2001 IMPROVE-2 Event. Part III: Simulated Microphysical Budgets and Sensitivity Studies, J. Atmos. Sci., 62, 3535-3558, https://doi.org/10.1175/JAS3552.1, 2005.

Conger, S. M. and McClung, D. M.: Comparison of density cutters for snow profile observations, J. Glaciol., 55, 163-169, 2009.

Dent, J., Burrell, K., Schmidt, D., Louge, M., Adams, E., and Jazbutis, T.: Density, velocity and friction measurements in a drysnow avalanche, Ann. Glaciol., 26, 247-252, 1998.

rfani, E. and Mitchell, D. L.: Growth of ice particle mass and projected area during riming, Atmos. Chem. Phys., 17, 1241-1257, https://doi.org/10.5194/acp-17-1241-2017, 2017.

Fabry, F. and Szyrmer, W.: Modeling of the Melting Layer. Part II: Electromagnetic, J. Atmos. Sci., 56, 3593-3600, 1999.

Fovell, R. G. and $\mathrm{Su}, \mathrm{H}$.: Impact of cloud microphysics on hurricane track forecasts, Geophys. Res. Lett., 34, L24810, https://doi.org/10.1029/2007GL031723, 2007.

Garrett, T. J. and Yuter, S. E.: Observed influence of riming, temperature, and turbulence on the fallspeed of solid precipitation, Geophys. Res. Lett., 41, 6515-6522, https://doi.org/10.1002/2014GL061016, 2014.

Garrett, T. J., Fallgatter, C., Shkurko, K., and Howlett, D.: Fall speed measurement and high-resolution multi-angle photography of hydrometeors in free fall, Atmos. Meas. Tech., 5, 26252633, https://doi.org/10.5194/amt-5-2625-2012, 2012.

Garrett, T. J., Yuter, S. E., Fallgatter, C., Shkurko, K., Rhodes, S. R., and Endries, J. L.: Orientations and aspect ratios of falling snow, Geophys. Res. Lett., 42, 4617-4622, https://doi.org/10.1002/2015GL064040, 2015.

Garvert, M. F., Woods, C. P., Colle, B. A., Mass, C. F., Hobbs, P. V., Stoelinga, M. T., and Wolfe, J. B.: The 1314 December 2001 IMPROVE-2 Event. Part II: Comparisons of MM5 Model Simulations of Clouds and Precipitation with Observations, J. Atmos Sci., 62, 3520-3534, https://doi.org/10.1175/JAS3551.1, 2005.

Heymsfield, A. J.: Properties of Tropical and Midlatitude Ice Cloud Particle Ensembles. Part II: Applications for Mesoscale and Climate Models, J. Atmos. Sci., 60, 2592-2611, 2003.

Heymsfield, A. J. and Westbrook, C. D.: Advances in the Estimation of Ice Particle Fall Speeds Using Laboratory 
and Field Measurements, J. Atmos. Sci., 67, 2469-2482, https://doi.org/10.1175/2010JAS3379.1, 2010.

Holroyd, E. W.: The meso-and microscale structure of Great Lakes snowstorm bands: A synthesis of ground measurements, radar data, and satellite observations, $\mathrm{PhD}$ thesis, State University of New York at Albany, Department of Atmospheric Science, 1971.

Hong, S., Dudhia, J., and Chen, S.: A Revised Approach to Ice Microphysical Processes for the Bulk Parameterization of Clouds and Precipitation, Mon. Weather Rev., 132, 103-120, https://doi.org/10.1175/15200493(2004)132<0103:ARATIM>2.0.CO;2, 2004.

Iguchi, T., Matsui, T., Shi, J. J., Tao, W.-K., Khain, A. P., Hou, A., Cifelli, R., Heymsfield, A., and Tokay, A.: Numerical analysis using WRF-SBM for the cloud microphysical structures in the C3VP field campaign: Impacts of supercooled droplets and resultant riming on snow microphysics, J. Geophys. Res., 117, D23206, https://doi.org/10.1029/2012JD018101, 2012.

Khvorostyanov, V. I. and Curry, J. A.: Terminal Velocities of Droplets and Crystals: Power Laws with Continuous Parameters over the Size Spectrum, J. Atmos. Sci., 59, 1872-1884, https://doi.org/10.1175/15200469(2002)059<1872:TVODAC>2.0.CO;2, 2002.

Kruger, A. and Krajewski, W. F.: Two-dimensional video disdrometer: A description, J. Atmos. Ocean. Tech., 19, 602-617, 2002.

Kubicek, A. and Wang, P. K.: A numerical study of the flow fields around a typical conical graupel falling at various inclination angles, Atmos. Res., 118, 15-26, https://doi.org/10.1016/j.atmosres.2012.06.001, 2012.

Lin, Y., Donner, L. J., and Colle, B. A.: Parameterization of Riming Intensity and Its Impact on Ice Fall Speed Using ARM Data, Mon. Weather Rev., 139, 1036-1047, https://doi.org/10.1175/2010MWR3299.1, 2010.

Liu, C., Ikeda, K., Thompson, G., Rasmussen, R., and Dudhia, J.: High-Resolution Simulations of Wintertime Precipitation in the Colorado Headwaters Region: Sensitivity to Physics Parameterizations, Mon. Weather Rev., 139, 3533-3553, 2011.

Locatelli, J. D. and Hobbs, P. V.: Fall speeds and masses of solid precipitation particles, J. Geophys. Res., 79, 2185-2197, https://doi.org/10.1029/JC079i015p02185, 1974.

Magono, C. and Nakamura, T.: Aerodynamic Studies of Falling Snowflakes, J. Meteorol. Soc. Jpn. Ser. II, 43, 139-147, https://doi.org/10.2151/jmsj1965.43.3_139, 1965.

Milbrandt, J. A., Yau, M. K., Mailhot, J., Bélair, S., and McTaggartCowan, R.: Simulation of an Orographic Precipitation Event during IMPROVE-2. Part II: Sensitivity to the Number of Moments in the Bulk Microphysics Scheme, Mon. Weather Rev., 138, 625642, https://doi.org/10.1175/2009MWR3121.1, 2010.

Muramoto, K.-i., Matsuura, K., and Shiina, T.: Measuring the Density of Snow Particles and Snowfall Rate, Electr. Commun. Jpn., 78, 71-79, https://doi.org/10.1002/ecjc.4430781107, 1995.
Newman, A. J., Kucera, P. A., and Bliven, L. F.: Presenting the Snowflake Video Imager (SVI), J. Atmos. Ocean. Tech., 26, 167179, https://doi.org/10.1175/2008JTECHA1148.1, 2009.

Rees, K. N., Singh, D. K., Pardyjak, E. R., and Garrett, T. J.: Mass and density of individual frozen hydrometeors and A differential emissivity imaging technique for measuring hydrometeors, The Hive: University of Utah Research Data Repository [data set], https://doi.org/10.7278/S50D-SPT1-FNHH, 2021.

Reisner, J., Rasmussen, R. M., and Bruintjes, R. T.: Explicit forecasting of supercooled liquid water in winter storms using the MM5 mesoscale model, Q. J. Roy. Meteor. Soc., 124, 10711107, https://doi.org/10.1256/smsqj.54803, 1998.

Rutledge, S. A. and Hobbs, P. V.: The Mesoscale and Microscale Structure and Organization of Clouds and Precipitation in Midlatitude Cyclones, XII: A Diagnostic Modeling Study of Precipitation Development in Narrow Cold-Frontal Rainbands, J. Atmos. Sci., 41, 2949-2972, https://doi.org/10.1175/15200469(1984)041<2949:TMAMSA>2.0.CO;2, 1984.

Shkurko, K., Gaustad, K., and Garrett, T. J.: Multi-Angles Snowflake Camera Value-Added Product, Tech. Rep. DOE/SCARM-TR-187, Department of Energy Atmospheric Radiation Measurement Program, 2016.

Singh, D. K., Donovan, S., Pardyjak, E. R., and Garrett, T. J.: A differential emissivity imaging technique for measuring hydrometeor mass and type, Atmos. Meas. Tech. Discuss. [preprint], https://doi.org/10.5194/amt-2021-44, in review, 2021.

Tao, W. K., Simpson, J., Baker, D., Braun, S., Chou, M. D., Ferrier, B., Johnson, D., Khain, A., Lang, S., Lynn, B. and Shie, C. L.: Microphysics, radiation and surface processes in the Goddard Cumulus Ensemble (GCE) model, Meteorol. Atmos. Phys., 82, 97-137, 2003.

Thériault, J. M., Stewart, R. E., and Henson, W.: Impacts of terminal velocity on the trajectory of winter precipitation types, Atmos. Res., 116, 116-129, https://doi.org/10.1016/j.atmosres.2012.03.008, 2012.

Tiira, J., Moisseev, D. N., von Lerber, A., Ori, D., Tokay, A., Bliven, L. F., and Petersen, W.: Ensemble mean density and its connection to other microphysical properties of falling snow as observed in Southern Finland, Atmos. Meas. Tech., 9, 4825-4841, https://doi.org/10.5194/amt-9-4825-2016, 2016.

Yuter, S. E., Kingsmill, D. E., Nance, L. B., and Löffler-Mang, M.: Observations of Precipitation Size and Fall Speed Characteristics within Coexisting Rain and Wet Snow, J. Appl. Meteorol. Clim., 45, 1450-1464, https://doi.org/10.1175/JAM2406.1, 2006. 